\title{
Identification of Volatile Compounds in Jellyfish Protein Hydrolysate
}

\author{
Isaree Kromfang, Utorn Chikhunthod, Pirin Karpilanondh and Benjawan Thumthanaruk* \\ Department of Agro-Industrial, Food and Environmental Technology, Faculty of Applied Science, King \\ Mongkut's University of Technology North Bangkok, Bangkok, Thailand \\ * Corresponding author. E-mail: btr@kmutnb.ac.th \\ Received: 2 June 2014; Accepted: 30 October 2014; Published online: 19 December 2014 \\ (C) 2015 King Mongkut's University of Technology North Bangkok. All Rights Reserved.
}

\begin{abstract}
In the present investigation, jellyfish protein hydrolysates (JPHs) of the umbrella or oral arm of the sand jellyfish (Rhopilema hispidum) and white jellyfish (Lobonema smithii) were produced by acetic acid hydrolysis with the aid of temperature and pressure. Volatile flavor compounds found in the hydrolysates were categorized into 6 groups: aldehydes (hexanal, heptanal, octanal, and 2-butyl-2-octenal), furan (2-butylfuran), terpene (beta-terpinol), alkane (2, 4-dimethyl undecane), acid (pterin-6-carboxylic acid), ester (isobornyl formate) and ketones ( $\beta$-ionone and propanone). Hexanal, heptanal and octanal that are indicators of fishy flavors were accentuated by acetic acid treatment.
\end{abstract}

Keywords: Jellyfish protein hydrolysate, Fishy flavor, Off flavor, Volatile flavor compound

\section{Introduction}

White jellyfish (Lobonema smithii) and sand jellyfish (Rhopilema hispidum) are the most important edible jellyfish species caught in Thailand. Apart from these two species, red type or China type (Rhopilema esculentum), river type (Acromitus flagellatus), prigi type (Crambione mastigophora), ball type (Crambionella orsi), cilacap type (Crambionella sp.) and one unidentified species (semi-China type) are commercially sold in the Southeast Asian market [1]. Salted jellyfish from Thailand are mainly exported to Japan, South Korea, Malaysia, China and Taiwan with a total value close to 10 million US dollar annually [2]. The typical salted jellyfish produced by salting with common salt (sodium chloride), alum (potassium aluminium sulfate) and soda (sodium bicarbonate) [3-4] generally have a marine, iodized or salty, fishy and slightly oxidized flavor. The major protein of processed jellyfish has been identified as collagen [1,3-6], but the production of jellyfish protein hydrolysate (JPH) has not been extensively studied due to the low availability of commercial salted jellyfish in the market.

Fisheries hydrolysate products generally have a fishy flavor, thus limiting their use in foods. Total volatile base nitrogen (TVB-N) and trimethylamine (TMA) are generally accepted as indicators of the lack of freshness for seafood products. The volatile compounds contributing to fishy flavor include alkanals (C5-C10), 2-alkenals (C5-C10), trans, trans-2, 4-heptadienal, 2 alkanones (C3-C11), 1-octen-3-one, cis, cis, trans-2, 4, 7-decatrienal and 1-penten-3-one [7]. Fishy flavor compounds of sardine (Sardinops melanostica) including hexanal, cis-4-heptenal, trans, cis-2, 6-nonadienal, 1-penten-3-one, 2, 3-pentanedione, methional and TMA have been identified [8]. Trimethylamine is a key compound of marine and fishy odors in sea fig (Microcosmus sulcatus) [9]. The key fishy compound in cooked American lobster tail meat was cis-4-heptenal while many other fishy volatile compounds remain unidentified [10]. On the other hand, dimethyl disulfide is recognized as the

Please cite this article as: I. Kromfang, U. Chikhunthod, P. Karpilanondh, and B. Thumthanaruk, "Identification of Volatile Compounds in Jellyfish Protein Hydrolysate," KMUTNB Int J Appl Sci Technol, Vol. 8, No. 2, pp. 153-161, Apr.-June 2015, http://dx.doi.org/10.14416/j.ijast.2014.10.003 
principal fishy volatile flavor compound from mussel (Mytilus edulis) [11]. Therefore, volatile compounds contributing to fishy flavor may vary from one product to another. The oxidation of polyunsaturated fatty acids (PUFAs) including oleic, linoleic, linolenic and arachidonic generates many volatile aldehydes, and causes rancid, oxidized or off-flavors [12] that reduce consumer acceptance. Acetic acid is a mild food acidulant with a potent vinegar flavor that has various applications in food products. Acetic acid, gluconic acid and trisodium acetate have been used to reduce or mask the fishy flavor or off flavors of processed sea food [13]. The aim of this study was to investigate volatile flavor compounds of JPHs prepared by acetic acid hydrolysis of the umbrella or oral arm portions of the white jellyfish (Lobonema smithii) and sand jellyfish (Rhopilema hispidum).

\section{Materials and Methods}

\subsection{Raw material}

The umbrella portion and oral arms of salted white jellyfish (Lobonema smithii) and sand jellyfish (Rhopilema hispidum) were purchased from Mahachai Seafood, Co., Ltd. Samutsakorn, Thailand. To maintain the quality of the salted jellyfish, the samples were stored at $10 \pm 2^{\circ} \mathrm{C}$ for 3 months in the sealed polyethylene bag.

\subsection{Chemicals}

Food grade acetic acid (5\%) was purchased from a local convenience store. Standards of nineteen amino acids with the purity $>99 \%$ were purchased from Sigma-Aldrich Ltd. (St. Louis, MO. USA). Thirty seven fatty acids (Food Industry FAME Mix, Restek) were purchased from C.E. Combination Co., Ltd, Nonthaburi, Thailand. All other chemicals used in this study were of analytical grade.

\subsection{Preparation of $\mathrm{JPH}$}

Salted jellyfish were washed with tap water 4 times to remove salt and impurities before being immersed in tap water overnight. The desalted jellyfish was drained for $30 \mathrm{~min}$ and then chopped into small pieces. The mince $(70 \mathrm{~g})$ was blended with $100 \mathrm{ml}$ of $0.01 \%$ acetic acid using a Moulinex blender. The same amount of mince mixed with distilled water was used as a control. The slurry was then autoclaved at $121^{\circ} \mathrm{C}, 15 \mathrm{lb} / \mathrm{in}^{2}$ for $15 \mathrm{~min}$. The homogenates were concentrated by a rotary evaporator (Rotavapor ${ }^{\circledR}$ R-210 Buchi Labortechnik AG, Glatthalde, Flawil, Switzerland) until the soluble solids were approximately $10^{\circ} \mathrm{Bx}$. The supernatant was filtered through filter paper to remove the non-hydrolyzed portion and kept frozen until analysis. In this study, the hydrolysates of the umbrella and oral arm of white jellyfish and sand jellyfish are referred to as UW-JPH, OW-JPH, US-JPH and OS-JPH, respectively.

\subsection{Analyses}

\subsubsection{Moisture}

Moisture of desalted jellyfish was determined according to AOAC method, 934.01 [14].

\subsubsection{Determination of total volatile bases nitrogen (TVB-N) and trimethylamine (TMA)}

TVB-N and TMA of desalted jellyfish were also measured. TVB-N was followed the method of Vyncke, et al. [15] and expressed as milligrams per $100 \mathrm{~g}$ of desalted jellyfish (wet weight). TMA was performed according to AOAC method, 971.14) [14].

\subsubsection{Determination of fatty acid profile}

Crude fat content was extracted with petroleum ether (AOAC method, 948.15) [14]. Fatty acid profiles of desalted jellyfish were analyzed. Fatty acid methyl ester was prepared using the boron trifluoride method Thirty seven fatty acids (Food Industry FAME Mix, Restek, C.E. Combination Co., Ltd, Nonthaburi, Thailand) were used as standards. One $\mu$ l of esterified JPH sample was injected onto a gas chromatograph (GC-6890, Agilent Technologies, Inc. Palo Alto, CA, USA) equipped with a polar biscyanopropyl column $(100 \mathrm{~m} \times 0.25 \mathrm{~mm}$ i.d $\times 0.2 \mu \mathrm{m}$ film, Supelco SPтм 2560, Sigma-Aldrich, St. Louis, MO. USA.) coupled to a flame ionization detector. The initial temperature of column was set to $100^{\circ} \mathrm{C}$ and held for $5 \mathrm{~min}$. The final temperature was set at $230^{\circ} \mathrm{C}$ with an increased rate of $4^{\circ} \mathrm{C}$ per min. The flow rate of the helium carrier gas was maintained at a constant rate of $0.8 \mathrm{ml} / \mathrm{min}$. 
The peaks of fatty acids were quantified and expressed as a percentage of the total fatty acids.

\subsection{4 pH measurement}

The $\mathrm{pH}$ measurements of JPHs in acetic acid solution $(20 \mathrm{ml})$ were performed using a $\mathrm{pH}$ meter (Cyberscan Model 500, Euteon Instrument, Singapore).

\subsubsection{Amino acid analysis}

Hydrolysate samples (50 mg) of UW-JPH, OW-JPH, US-JPH and OS-JPH were hydrolyzed in $5 \mathrm{ml}$ of $6 \mathrm{~N}$ $\mathrm{HCl}$ at $110^{\circ} \mathrm{C}$ for $24 \mathrm{hr}$ in a block heater (Model SBH 130D, Stuart Scientific, Manchester, UK). After the samples were concentrated by flushing with nitrogen gas, they were adjusted to $5 \mathrm{ml}$ with distilled water and filtered through a $0.45 \mu \mathrm{m}$ cellulose acetate filter (VertiPure ${ }^{\mathrm{TM}}$ CA Syringe Filter, Vertical Chromatography Co., Ltd. Bangkok, Thailand). Amino acid analysis was performed according to the method of Yan et al., [16]. Briefly, a $10 \mu \mathrm{l}$ aliquot of each sample was analyzed by reverse phase-high performance liquid chromatography (RP-HPLC Model 1200, Agilent Technologies, Inc. Santa Clara, CA, USA) on a fused silica capillary $(\mathrm{C} 18 ; 250 \mathrm{~mm} \times$ 4.6 i.d., $5 \mu \mathrm{m}$ film thickness; Prevail ${ }^{\mathrm{TM}}$ column Alltech $^{\circledR}$, Deerfield, IL, USA). Mobile phase used was $5 \mathrm{mM}$ heptafluorobutyric acid (HFBA) in $0.5 \%$ trifluoroacetic acid (TFA) (A) and acetonitrile: $\mathrm{H}_{2} \mathrm{O}$ (95:5) (B). Gradient conditions of B were $0,0,15$, $35 \%$ at $0,3,8$ and $17 \mathrm{~min}$, respectively. Flow rate used was $1.0 \mathrm{ml} / \mathrm{min}$.

\subsubsection{Identification of volatile compounds in JPHs by headspace GC-MS}

Hydrolysates $(5 \mathrm{ml})$ were packed in a $10 \mathrm{ml}$ brown vial for the headspace technique. The samples were heated at $85^{\circ} \mathrm{C}$ for $30 \mathrm{~min}$ in a GC-MS heating block. Using a $2.5 \mathrm{ml}$ gastight syringe with a 23 gauge part no. 5 needle (Model 1002 LTN CTC, Hamilton Bonaduz AG., Bonaduz, GR, Switzerland), a $1 \mathrm{ml}$ sample was injected into a gas chromatograph-mass spectrometer (HP 5890, Agilent Technologies, Inc. Palo Alto, CA, USA). Volatile compounds were separated using HP-3MS capillary column $(30 \mathrm{~m}$ length $\times 0.25 \mathrm{~mm}$ i.d.; coated film thickness: $0.25 \mu \mathrm{m})$. The operating temperature program was initially maintained at $40^{\circ} \mathrm{C}$ for $2 \mathrm{~min}$, then increased to $250^{\circ} \mathrm{C}$ at $4^{\circ} \mathrm{C}$ per min, and finally held at $250^{\circ} \mathrm{C}$ for $10 \mathrm{~min}$. The injection temperature was set at $220^{\circ} \mathrm{C}$ on the splitless mode. Helium gas $(99.99 \%)$ was used a carrier at a flow rate of $1.5 \mathrm{ml} / \mathrm{min}$. The mass spectrometer $(5975$ C inert XL EI/CI MSD with a triple-axis detector, Agilent Technologies, Inc. Santa Clara, CA, USA) was operated in scan mode from m/z 40 to 450 , with $70 \mathrm{eV}$ at $230^{\circ} \mathrm{C}$. The volatile flavor compounds were identified by first comparing their mass spectrum with those in Wiley 275 and the NIST library at percentage of quality match over $85 \%$ and compared with previously published literature, followed by retention index (RI values) of JPHs, which was calculated against the standard alkanes C11-C20 using the equation proposed by Van den Dool and Kratzs [17] as indicated below.

$$
\mathrm{RI}=100([\operatorname{Rt}(\mathrm{x})-\operatorname{Rt}(\mathrm{z})] /[\operatorname{Rt}(\mathrm{z}+1)-\operatorname{Rt}(\mathrm{z})])+100 \mathrm{Z}
$$

Where $\operatorname{Rt}(\mathrm{x})$ : retention time ( $\mathrm{min})$ of the interested compound

$\operatorname{Rt}(\mathrm{z})$ : retention time (min) of normal alkane

$\operatorname{Rt}(\mathrm{z}+1)$ : retention time (min) of $\mathrm{z}+1$ normal alkane

$\mathrm{Z}$ : the number of carbon atoms

\subsection{Statistical analysis}

The analyses of moisture, TVB-N, TMA and $\mathrm{pH}$ were performed in triplicate while the determinations of amino acid, fatty acid profile, and volatile compounds were carried out in duplicate. The data were analyzed by SPSS and Duncan's multiple range test was used to determine the significant differences $(p<0.05)$ among means [18].

\section{Results and Discussion}

\subsection{Chemical quality of desalted jellyfish}

All desalted jellyfish samples showed no significant difference in moisture. The moisture content of white and sand jellyfish was approximately $95 \%$. The analysis of fatty acid profile of desalted samples was performed due to the fact that polyunsaturated fatty 
acid may produce oxidized flavor compound during hydrolysis. No short chain fatty acids were found in all desalted samples. These two types of desalted jellyfish had medium and long chain fatty acids (Table 1 ). The $\omega-6$ fatty acids found in both desalted jellyfish were linoleic acid and arachidonic acid. Additionally, the $\omega-3$ fatty acids including cis- $9,12,15$-octadecatrienoic acid and cis-5, 8, 11, 14, 17-eicosapentaenoic acid were found only in the umbrella and oral arm portions of sand jellyfish. Although the amount of polyunsaturated fatty acid in desalted jellyfish was low, oxidation of these fatty acids could occur during storage [19].

TVB-N and TMA compounds are commonly used as indicators of the (lack of) freshness of seafood.
The TVB-N contents of umbrella and oral arm of desalted white jellyfish and sand jellyfish were $12.8 \pm 0.20,17.5 \pm 0.29,12.8 \pm 0.40$ and $15.2 \pm 0.53$ $\mathrm{mg} / 100 \mathrm{~g}$, while that of TMA was $8.2 \pm 0.20,7.0 \pm 0.00$, $7.0 \pm 0.00$ and $9.3 \pm 0.20 \mathrm{mg} / 100 \mathrm{~g}$, respectively. The TVB-N level was below the range of $30-35 \mathrm{mg} / 100 \mathrm{~g}$ that is the acceptability limit for ice stored cold-water fish [20-21]. The high content of both TVB-N and TMA suggests that, in general, the jellyfish might already be at an initial stage of decomposition prior to salting; hence, the typical intense fishy flavor could detect from salted jellyfish samples. In this study, the washing step with water several times can reduce the fishy and salty smell of the salted samples.

Table 1: Profile of fatty acid of desalted jellyfish samples*

\begin{tabular}{|c|c|c|c|c|c|}
\hline \multirow{3}{*}{ Type of fatty acid } & \multirow{3}{*}{ RT (min) } & \multicolumn{4}{|c|}{$\%$ Fatty acid } \\
\hline & & \multicolumn{2}{|c|}{$\begin{array}{c}\text { white jellyfish } \\
\text { (Lobonema smithii) } \\
\end{array}$} & \multicolumn{2}{|c|}{$\begin{array}{c}\text { sand jellyfish } \\
\text { (Rhopilema hispidum) }\end{array}$} \\
\hline & & umbrella & oral arm & umbrella $^{3}$ & oral arm $^{4}$ \\
\hline \multicolumn{6}{|l|}{ Saturated } \\
\hline dodecanoic acid & 23.53 & 0.52 & 0.87 & $<0.00$ & 0.43 \\
\hline tetradecanoic acid & 27.54 & 7.92 & 4.67 & 2.77 & 3.28 \\
\hline pentadecanoic acid & 29.40 & 2.23 & 1.87 & 1.19 & 1.29 \\
\hline hexadecanoic acid & 31.16 & 43.64 & 40.81 & 39.76 & 40.68 \\
\hline heptadecanoic acid & 32.83 & 2.71 & 3.79 & 3.24 & 3.27 \\
\hline octadecanoic acid & 34.43 & 17.64 & 23.06 & 21.31 & 22.68 \\
\hline eicosanoic acid & 37.42 & 1.08 & 1.85 & 0.98 & 1.46 \\
\hline heneicosanoic acid & 38.85 & 0.71 & 0.55 & 0.36 & 0.37 \\
\hline docosanoic acid & 40.32 & 1.34 & 1.35 & 0.84 & 0.71 \\
\hline Tricosanoic acid & 41.91 & $<0.00$ & $<0.00$ & 0.20 & 0.17 \\
\hline Tetracosanoic acid & 43.50 & 1.33 & 1.16 & 0.82 & 0.79 \\
\hline Total & & 79.12 & 79.98 & 71.47 & 75.13 \\
\hline \multicolumn{6}{|l|}{ Monounsaturated } \\
\hline cis-9-tetradecenoic acid & 29.09 & $<0.00$ & $<0.00$ & 0.70 & $<0.00$ \\
\hline cis-10-pentadecenoic acid & 30.89 & $<0.00$ & $<0.00$ & $<0.00$ & $<0.00$ \\
\hline cis-9-hexadecenoic acid & 32.37 & 6.86 & 2.83 & 3.69 & 2.69 \\
\hline cis-10-heptadecenoic acid & 34.01 & $<0.00$ & $<0.00$ & $<0.00$ & 0.11 \\
\hline cis-9-octadecenoic acid & 35.43 & 4.18 & 6.27 & 7.13 & 5.38 \\
\hline cis-11-eicosenoic acid & 38.36 & $<0.00$ & $<0.00$ & $<0.00$ & 1.00 \\
\hline cis-15-tetracosenoic acid & 44.69 & 0.72 & 0.74 & 0.42 & 0.40 \\
\hline Total & & 11.76 & 9.84 & 11.94 & 9.58 \\
\hline \multicolumn{6}{|l|}{ Polyunsaturated } \\
\hline cis-9,12-octadecadienoic acid & 36.91 & 0.51 & 1.08 & 1.46 & 0.61 \\
\hline cis-9,12,15-octadecatrienoic acid & 38.59 & $<0.00$ & $<0.00$ & $<0.00$ & 0.23 \\
\hline cis-13,16-docosadienoic acid & 41.34 & $<0.00$ & $<0.00$ & 0.10 & 0.53 \\
\hline cis-11,14,17-eicosatrienoic acid & 41.62 & $<0.00$ & $<0.00$ & 0.12 & $<0.00$ \\
\hline cis-5,8,11,14-eicosatetraenoic acid & 41.85 & 0.56 & 0.36 & 0.22 & 0.27 \\
\hline Cis-5,8,11,14,17-eicosapentaenoic acid & 44.00 & $<0.00$ & $<0.00$ & 0.36 & $<0.00$ \\
\hline Total & & 1.07 & 1.44 & 2.26 & 1.64 \\
\hline
\end{tabular}

Remark.

*The umbrella and oral arm of desalted white jellyfish and those of sand jellyfish had the moisture content of 93.52, 92.59, 95.12 and $93.75 \%$, respectively. The calculation was based on wet weight basis. 


\subsection{Quality of JPHs}

The type of amino acid is associated with taste and flavor in food products. Amino acid analysis of all JPHs contained collagen as indicated by their hydroxyproline content (Table 2). Published data for Stomolophus meleagris [5] and Rhopilema esculentum [22] showed that these species have similar amino acid profiles with only minor differences in amino acid content. The amino acid profiles show considerable differences as compared with those of Rhopilema hispidum and Lobonema smithii. In this study, all hydrolysates had almost all of the essential amino acids, except tryptophan. Tryptophan is an acid labile amino acid which may be destroyed during hydrolysate preparation and amino acid determination [23]. Compared with other JPHs, the present results revealed that, in most cases, JPHs had higher contents of the essential amino acids lysine and threonine (Table 2). Non-essential amino acids including glutamic acid, arginine and tyrosine were also higher in all JPHs (Table 2). JPHs typically give a marine, iodized or salty and oxidized flavor as well as a fishy flavor. When acetic acid was used, it had an additional positive impact owing to the fact that the mild vinegar flavor could partially mask the fishy flavor in the hydrolysate products. However, hydrolysates with an excessively high vinegar flavor would also decrease consumer acceptance. In this study, the condition used for producing JPHs was $0.01 \%$ acetic acid and pressure $\left(15 \mathrm{lb} / \mathrm{in}^{2}\right)$ at $121^{\circ} \mathrm{C}$. A pH range of all the obtained JPH is between 3.80-3.86. Mild acid hydrolysis under elevated temperature and pressure could destabilize hydrogen bonds and promote hydrophobic and electrostatic interactions, resulting in hydrolysis of the collagen helix [24]. Together with the characteristic vinegar flavor of acetic acid, all JPHs had less 2-butyl2-octenal and pterin-6-carboxylic acid. The results of this investigation suggested that acetic acid could suppress some flavors of JPHs.

Table 2: Amino acid profile of JPHs

\begin{tabular}{|c|c|c|c|c|c|c|}
\hline \multirow[b]{2}{*}{ Type of amino acid } & \multicolumn{6}{|c|}{ Sample } \\
\hline & $\begin{array}{c}\text { US-JPH* } \\
\text { (residue/ } \\
1000 \text { residue) }\end{array}$ & 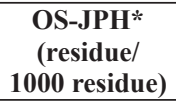 & $\begin{array}{c}\text { UW-JPH* } \\
\text { (residue/ } \\
1000 \text { residue) } \\
\end{array}$ & $\begin{array}{c}\text { OW-JPH* } \\
\text { (residue/ } \\
1000 \text { residue) }\end{array}$ & $\begin{array}{c}\text { pepsin-solubilised } \\
\text { jellyfish collagen } 1 \\
\text { (residue/ } 1000 \text { residue) }\end{array}$ & $\begin{array}{c}\text { jellyfish } \\
\text { hydrolysate } \\
\text { (mg/100g) }\end{array}$ \\
\hline \multicolumn{7}{|c|}{$e^{2}$} \\
\hline histidine & 7 & 14 & 8 & 7 & 2 & 4.4 \\
\hline isoleucine & 20 & 21 & 19 & 18 & 22 & 27.7 \\
\hline leucine & 30 & 33 & 33 & 31 & 34 & 35.5 \\
\hline lysine & 161 & 70 & 97 & 87 & 38 & 26.9 \\
\hline methionine & 10 & 16 & 12 & 11 & 4 & 14.3 \\
\hline phenylalanine & 13 & 15 & 12 & 11 & 10 & 16.8 \\
\hline threonine & 53 & 53 & 51 & 52 & 35 & 28.9 \\
\hline valine & 26 & 28 & 26 & 25 & 35 & 55.6 \\
\hline \multicolumn{7}{|l|}{ Non-essential } \\
\hline alanine & 56 & 60 & 55 & 57 & 82 & 84.8 \\
\hline arginine & 67 & 77 & 73 & 74 & 52 & 50.6 \\
\hline aspartic acid & 78 & 77 & 81 & 83 & 79 & 85.4 \\
\hline glutamic acid & 114 & 111 & 113 & 116 & 98 & 90.8 \\
\hline glycine & 209 & 233 & 244 & 252 & 309 & 289.5 \\
\hline hydroxyproline & 46 & 67 & 62 & 61 & 40 & 45.2 \\
\hline proline & 62 & 73 & 66 & 73 & 82 & 85.4 \\
\hline serine & 34 & 38 & 35 & 32 & 45 & 45.5 \\
\hline tyrosine & 12 & 17 & 14 & 13 & 6 & 12.4 \\
\hline Sum & 1000 & 1000 & 1000 & 1000 & 1000 & 999.7 \\
\hline
\end{tabular}

Remark.

US-JPH referred to hydrolysate from umbrella of sand jellyfish

OS-JPH referred to hydrolysate from oral arm of sand jellyfis

UW-JPH referred to hydrolysate from umbrella of white jellyfish

OW-JPH referred to hydrolysate from oral arm of white jellyfish

${ }^{1}$ results of Stomolophus meleagris [5]

${ }^{2}$ results of Rhopilema esculentum [22]

*The data obtained was based on wet weight basis 
However, the fishy flavor is quite different from that obtained from spoiled fish. In this study, the contents of a number of volatile flavor compounds of white jellyfish (UW-JPH and OW-JPH) were higher compared to those of sand jellyfish (US-JPH and OS-JPH) (Tables 3 and 4). A total of 9 identified volatile compounds and 2 unknown were discovered in UW-JPH and OW-JPH, while 8 identified compounds were found in US-JPH and OS-JPH. The results revealed that different species and portions of salted jellyfish had slightly different flavor characteristics. Moreover, gas chromatography results indicated that most of the acid hydrolyzed JPHs had increased relative peak areas as compared with the water hydrolyzed JPHs which were used as control samples in this study. The acid hydrolysis reduced the levels of 2, 4-dimethyl undecane and of two unknown compounds of UW-JPH and OW-JPH and the levels of 2- butylfuran, propanone and pterin-6-carboxylic acid of US-JPH and OS-JPH (Tables 3 and 4).

Table 3: Flavor compounds found in protein hydrolysates of white jellyfish

\begin{tabular}{|c|c|c|c|c|c|c|}
\hline \multirow{2}{*}{ Flavor compound } & \multirow{2}{*}{$\begin{array}{c}\text { RI } \\
\text { (Retention index) }\end{array}$} & \multicolumn{4}{|c|}{$\%$ relative peak area } & \multirow{2}{*}{ odor description* } \\
\hline & & control & UW-JPH & control & OW-JPH & \\
\hline hexanal & 810 & 7.19 & 31.15 & 6.69 & 31.69 & grass, fishy, tallow, fat \\
\hline heptanal & 851 & 2.31 & 3.04 & 3.46 & 8.02 & fat, citrus, rancid \\
\hline unknown & 886 & 2.67 & - & 4.18 & - & - \\
\hline 2-butylfuran & 894 & - & 7.43 & - & 7.42 & $\begin{array}{c}\text { non-characteristic, } \\
\text { weak spicy }\end{array}$ \\
\hline unknown & 917 & 17.34 & - & 15.34 & - & - \\
\hline octanal & 1000 & - & 5.71 & - & 5.88 & fat, green \\
\hline 2-butyl-2-octenal & 1126 & 7.66 & 12.54 & 6.53 & 18.22 & meat \\
\hline \multicolumn{7}{|l|}{ 2,4-dimethyl } \\
\hline undecane & 1198 & 5.93 & - & 4.53 & - & - \\
\hline$\beta$-ionone & 1423 & 3.55 & 18.67 & 3.51 & 11.26 & floral, woody, sweet \\
\hline propanone & 1435 & 3.91 & 9.47 & 3.75 & 6.54 & - \\
\hline pterin-6-carboxylic acid & 1968 & 49.47 & 11.94 & 50.11 & 10.42 & - \\
\hline
\end{tabular}

Remark

UW-JPH referred to the hydrolysate from umbrella of white jellyfish

OW-JPH referred to the hydrolysate from oral arm of white jellyfish

*odor description [32]

Table 4: Flavor compound found in protein hydrolysates of sand jellyfish

\begin{tabular}{|c|c|c|c|c|c|c|}
\hline \multirow{2}{*}{ Flavor compound } & \multirow{2}{*}{\begin{tabular}{|c|} 
RI \\
(Retention index)
\end{tabular}} & \multicolumn{4}{|c|}{$\%$ relative peak area } & \multirow{2}{*}{ odor description* } \\
\hline & & control & US-JPH & control & OS-JPH & \\
\hline hexanal & 810 & 30.60 & 31.69 & 41.73 & 38.78 & grass, fishy, tallow, fat \\
\hline heptanal & 851 & 7.04 & 7.99 & 7.80 & 11.15 & fat, citrus, rancid \\
\hline 2-butylfuran & 894 & 11.40 & 8.42 & 10.50 & 8.16 & $\begin{array}{c}\text { non-characteristic, } \\
\text { weak spicy }\end{array}$ \\
\hline octanal & 1000 & - & 9.27 & - & 7.14 & fat, green \\
\hline 2-butyl-2-octenal & 1126 & 11.75 & 22.02 & 6.05 & 2.60 & meat \\
\hline 2,4-dimethyl undecane & 1198 & 7.24 & - & 4.53 & 8.37 & - \\
\hline propanone & 1435 & 6.48 & 4.54 & 6.51 & - & - \\
\hline pterin-6-carboxylic acid & 1968 & 25.46 & 10.62 & 22.84 & 20.00 & - \\
\hline
\end{tabular}

Remark

US-JPH referred to the hydrolysate from umbrella of sand jellyfish

OS-JPH referred to the hydrolysate from oral arm of sand jellyfish

*odor description [32]. 
The alkane, 2, 4-dimethyl undecane, was also reduced in US-JPH but increased in OS-JPH. All eight volatile flavor compounds were identical in sand jellyfish (US-JPH and OS-JPH) and white jellyfish (UW-JPH and OW-JPH), except that white jellyfish hydrolysates had additionally $\beta$-ionone and two unknown compounds (Tables 3 and 4 ). Identified volatile flavor compounds were classified into 6 groups that encompassed 4 aldehydes (hexanal, heptanal, octanal, and 2-butyl-2-octenal), furan (2-butylfuran), terpene (beta-terpinol), alkane (2, 4-dimethyl undecane), acid (pterin-6- carboxylic acid), ester (isobornyl formate) and 2 ketones ( $\beta$-ionone and propanone).

Volatile aldehydes including hexanal, heptanal and octanal detected in all JPHs demonstrated fishy, oily or fatty flavors. However, no TVB-N or TMA was detected since $\mathrm{pH}$ of the hydrolysate was acidic $\mathrm{pH}$ (3.8), so that volatile base was ionic and was not well volatilized. Octanal, which has a fatty pungent flavor, was found mostly in hydrolysates of sand jellyfish. Fishy, fatty, rancid or unpleasant odors in these JPHs could have been derived from lipid oxidation $[8,12,19,25]$, as in the case with other processed marine products during storage. 2-Butylfuran was found in all JPHs. A furan could have been derived from Maillard reactions that occurred during the heating and sample concentration step by rotary evaporation $[12,26]$. Small quantities of $\beta$-ionone and propanone found in the hydrolysates could have originated from the degradation products of algae that are symbiotic with jellyfish. $\beta$-ionone that contributes to floral and woody flavors was evident particularly in UW-JPH. The ketone could be attributed to the beta-carotene compounds constituting in foods that jellyfish consumed [27], which were afterwards oxidized during storage. These compounds would have accumulated in the jellyfish and oxidized during storage. Pterin-6-carboxylic acid is the end product of folic acid degradation that yields $p$-aminobenzoylL-glutamic acid and 6-formyl pterin. Exposed to ultraviolet radiation, 6-formyl pterin is transformed to pterin-6-carboxylic acid [28]. 2-butyl-2-octenal has identified in fresh lamp [29] and cured pork [30] and so its presence in jellyfish is not surprising. Due to the fact that jellyfish comprises mainly water, they easily absorb and accumulate water-soluble contaminating compounds that potentially add to off flavors in the product. Guttman and Van Rijn reported that geosmin and 2-methyl isoborneol produced by cyanobacteria, fungi or actinomyces caused earthy-musty or off flavor in fish such as tilapia [31]. From the results of this study, GC-olfactometry (GC-O) may have to be deployed to further characterize the JPHs.

\section{Conclusions}

Jellyfish can be hydrolyzed by mild acetic acid with the aid of heat and pressure to produce protein hydrolysates. The hydrolysates of the two types of jellyfish, white jellyfish and sand jellyfish, showed slight differences in amino acid content and odor. Hydrolysates of jellyfish protein had marine, salty or iodized, oxidized and fishy flavor. The compounds hexanal, heptanal, 2-butylfuran, octanal, 2-butyl2-octenal, 2, 4 dimethyl undecane, $\beta$-ionone, propanone and pterin-6-carboxylic acid were detected in JPHs. Acetic acid may enhance the aldehyde volatiles (hexanal, heptanal and octanal), but it may mask the flavors from 2-butyl-2-octenal and pterin-6-carboxylic acid of JPHs. JPHs with low fishy flavor may be used as a functional and/or seasoning ingredient in food products.

\section{Acknowledgements}

We are grateful to Miss Sakuntala Phupornwiwat, Mrs. Somjai Suwanachai, Mr. Nitiwat Theranantakul and many fishermen who gave valuable information regarding the jellyfish fisheries industry in Thailand. We acknowledge with thanks Prof. Grady Chism who proofread this manuscript. We thank Graduate College and King Mongkut's University of Technology for providing financial support in the fiscal year of 2008-2010.

\section{References}

[1] M. Omori and E. Nakano, "Jellyfish fisheries in southeast asia," Hydrobiologia, vol. 451, pp. 19-26, 2001.

[2] Thai customs department. (2011, Aug.). Import/ export statistics. [Online]. Available: http://www. customs.go.th/Statistic/Statistic Index.jsp

[3] Y-H. P. Hsieh, F-M. Leong, and J. Rudloe, "Jellyfish as food," Hydrobiologia, vol. 451, 
pp. 11-17, 2001.

[4] P. Wongsa-Ngasri, P. Virulhakul, and B. Thumthanaruk, "Study of salted jellyfish production in commercial," Fishery Technological Development Div., Dept of Fisheries. No.9, 2008.

[5] T. Nagai, T. Ogawa, T. Nakamura, T. Ito, H. Nakagawa, K. Fujiki, M. Nakao, and T. Yano, "Collagen of edible jellyfish exumbrella," J. Sci. Food Agric., vol. 79, pp. 855-858, 1999.

[6] T. Nagai, W. Worawattanamateekul, N. Suzuki, T. Nakamura, T. Ito, K. Fujiki, M. Nakao, and T. Yano, "Isolation and characterization of collagen from rhizostomous jellyfish (Rhopilema asamushi)," Food Chem., vol. 70, pp. 205-208, 2000.

[7] G. Reineccius, "Off-Flavors and Taints in Flavor Chemistry and Technology" in Flavor Chemistry and Technology, Florida: CRC Press. Taylor \& Francis Group. 2006.

[8] N. Ganeko, M. Shoda, I. Hirohara, A. Bhadra, T. Ishida, H. Matsuda, H. Takamura, and T. Matoba, "Analysis of Volatile Flavor Compounds of Sardine (Sardinops melanostica) by Solid Phase Microextraction," J. Food Sci., vol. 73(1), pp. S83-S87. 2008.

[9] P. Senger-Emonnot, S. Rochard, F. Pellegrin, G. George, X. Fernandez, and L. Lizzani-Cuvelier, "Odour active aroma compounds of sea fig (Microcosmus sulcatus)," Food Chem., vol. 97, pp.465-471, 2006.

[10] G.H. Lee, O. Suriyaphan, and K.R. Cadwallader, "Aroma components of Cooked Tail Meat of American Lobster (Homarus americanus)," J. Agric. Food Chem, vol. 49(9), pp. 4324-4332. 2001.

[11] S. Le Guen, C. Prost, and M. Demaimay, "Characterization of odorant compound of Mussel (Mytilus edulis) according to their origin using gas chromatography-olfactometry and gas chromatography-mass spectrometry," J. Chromatogr A, vol. 896, pp. 361-371, 2000.

[12] V. Varlet, C. Prost, and T. Serot, "Volatile aldehydes in smoked fish: Analysis methods, occurrence and mechanism of formation," Food Chem., vol. 105, pp. 1536-1556, 2007.

[13] M.R. Stivarius, F.W. Pohlman, K.S. McElyea, and J.K. Apple, "The effects of acetic acid, gluconic acid and trisodium citrate treatment of beef trimmings on microbial, color and odor characteristics of ground beef through simulated retail display," Meat Sci., vol. 60, pp. 245-252, 2002.

[14] AOAC. Official methods of analysis, 17th ed., Gaithersburg, MD, USA: Association of Official Chemists. 2000.

[15] W. Vyncke, J. Luten, K. Brünner, and R. Moermans, "Determination of total volatile bases in fish: a collaborative study by the West European Fish Technologists' Association (WEFTA)," Z. Lebens. Unters. Forsch., vol. 184, pp. 110-114, 1987.

[16] D. Yan, G. Li, X-H. Xiao, X-P. Dong, and Z-L. Li, "Direct determination of fourteen underivatized amino acids from Whitmannia pigra by using liquid chromatography-evaporative light scattering detection," J. Chromatogr A, vol. 1138, pp. 301304, 2007.

[17] H. Van den Dool and P.D. Kratz, "A generation of the retention index system including linear temperature programmed gas-liquid partition chromatography," J. Chromatogr A, vol. 11, pp. 463-471, 1963.

[18] SPSS Statistics, Version 18, SPSS Inc., CA, USA, 2011.

[19] F. Shahidi, Flavor of meat, meat products, and seafoods, London: Blackie Academic and Professional, 1998.

[20] J.J. Connell, Control of fish quality, (4th ed.), England: Fishing New Book Ltd., Farnham Survey, 1995, pp. 157, 159-160.

[21] H.H. Huss, Fresh fish quality and quality changes, Roma: FAO Fisheries Series No.29, 1988.

[22] Y. Zhuang, H. Hou, X. Zhao, Z. Zhang, and B. Li, "Effect of collagen and collagen hydrolysate from jellyfish (Rhopilema esculentum) on mice skin photoaging induced by UV irradiation," J. Food Sci., vol. 74(9), pp. 183-188, 2009.

[23] L. Joergensen and H.N. Thestrup, "Determination of amino acids in biomass and protein samples by microwave hydrolysis and ion-exchange chromatography," J. Chromatogr A, vol. 706, pp. 421-428, 1995.

[24] J. Engel and H.P. Bächinger, "Structure, Stability and Folding of the Collagen Triple Helix," Topic in Current Chem., vol. 247, pp. 7-33, 2005.

[25] A. Giri, A. K. Osako, A. Okamoto, and T. Ohshima, "Olfactometric characterization of aroma active 
compounds in fermented fish paste in comparison with fish sauce, fermented soy sauce and sauce products," Food Res. Int., vol. 43, pp. 1027-1040, 2010.

[26] M. A. J. S. Van Boekel, "Formation of flavor compounds in the Maillard reaction," Biotech. Adv., vol. 24, pp. 230-233, 2006.

[27] J. Dong, L. Jiang, K. Tan, H. Liu, J.E. Purcell, P. Li, and C. Ye, "Stock enhancement of the edible jellyfish (Rhopilema esculentum Kishinouye) in Liaodong bay, China," Hydrobiologia, vol. 616, pp. 113-118. 2009.

[28] M.K. Off, A.E. Steindal, A.C. Porojnicu, A. Juzeniene, A. Vorobey, A. Johnsson, and J. Moan, "Ultraviolet photodegradation of folic acid," J. Photochem Photobiol B: Biol, vol. 80, pp. 47-55. 2005.
[29] M. Bueno, V.C. Resconi, M.M. Campo, J. Cacho, V. Ferreira, andA. Escudero, "Gas chromatographicolfactometric characterisation of headspace and mouthspace key aroma compounds in fresh and frozen lamb meat," Food Chem., vol. 129, pp. 1909-1928, 2011.

[30] N. Ramarathnam, L.J. Rubin, and L.L. Diosady, "Studies on meat flavor: A novel method for trapping volatile components from uncured and cured pork," J. Agric. Food Chem., vol. 41(6), pp. 933-938, 1993.

[31] L. Guttman and J. Van Rijn, "Identification of conditions underlying production of geosmin and 2-methylisoborneol in a recirculating system," Aquaculture, vol. 279, pp. 85-91, 2008.

[32] Odor description [2010, Sep. 24] [Online]. Available: http://flavornet.org/flavornet.htm 